\title{
RP11-156L14.1 regulates SSR1 expression by competitively binding to miR-548ao-3p in hypopharyngeal squamous cell carcinoma
}

\author{
JING YAN* ${ }^{*}$ ZHENG-HUI WANG* , YAN YAN, HUA-NAN LUO, \\ XIAO-YONG REN, NA LI, GUO-XI ZHENG and JIN HOU \\ Department of Otorhinolaryngology Head and Neck Surgery, Second Affiliated Hospital of \\ Xi'an Jiaotong University, Xi'an, Shaanxi 710004, P.R. China \\ Received January 19, 2020; Accepted July 9, 2020
}

DOI: $10.3892 /$ or.2020.7762

\begin{abstract}
Emerging studies have demonstrated that long non-coding RNAs (lncRNAs) play essential roles in tumorigenesis. However, the role and function of lncRNAs in hypopharyngeal squamous cell carcinoma (HSCC) have not been completely elucidated. The present study explored the function of a novel lncRNA, RP11-156L14.1, in HSCC. RP11-156L14.1 was revealed to be highly expressed in HSCC tissues and cell lines. Knockdown of RP11-156L14.1 inhibited proliferation, migration, and invasion in HSCC cells Furthermore, RP11-156L14.1 regulated epithelial-mesenchymal transition (EMT) by controlling EMT-related protein expression. Mechanistically, RP11-156L14.1 exerted its function as a competing endogenous RNA (ceRNA) and directly interacted with miR-548ao-3p. The present study also demonstrated that miR-548ao-3p regulated signal sequence receptor subunit 1 (SSR1) expression by targeting SSR1 3'-UTR. Moreover, the xenograft HSCC tumor model revealed that knockdown of RP11-156L14.1 markedly suppressed HSCC tumor growth in vivo. In summary, these findings indicated that the lncRNA RP11-156L14.1 functions as an oncogene in HSCC by competing with miR-548ao-3p in regulating SSR1 expression. The RP11-156L14.1/miR-548ao-3p/SSR1 axis could be utilized as a potential novel biomarker and therapeutic target for HSCC.
\end{abstract}

Correspondence to: Dr Jin Hou or Dr Guo-Xi Zheng, Department of Otorhinolaryngology Head and Neck Surgery, Second Affiliated Hospital of Xi'an Jiaotong University, 157 West 5th Road, Xi'an, Shaanxi 710004, P.R. China

E-mail: 13319251982@126.com

E-mail: zhengguoxi@21cn.com

${ }^{*}$ Contributed equally

Key words: long non-coding RNAs, hypopharyngeal squamous cell carcinoma, signal sequence receptor subunit 1, miR-548ao-3p

\section{Introduction}

Hypopharyngeal squamous cell carcinoma (HSCC) is an aggressive tumor that develops in the hypopharynx (1). It accounts for $5 \%$ of all head and neck squamous cell carcinomas (2). Although HSCC therapy has markedly advanced over the past few decades, the 5-year survival rate of patients with HSCC remains lower than $50 \%$ due to diagnosis at late stages and tumor recurrence or metastasis $(3,4)$. Thus, understanding the oncogenic mechanisms underlying HSCC and identifying novel biomarkers for the early diagnosis of HSCC would be critical in improving diagnosis, therapeutic strategies, and prognosis in HSCC treatment.

Long noncoding RNAs (lncRNAs) account for the majority of transcripts and functional RNAs with more than 200 nucleotides (5). Mounting evidence has documented that lncRNAs are critical players in the development and metastasis of cancers, including HSCC $(6,7)$. Qian et al reported that lncRNA UCA1 regulates the proliferation, invasion, and survival of HSCC cells (8). AB209630 and PEG10 have also been demonstrated to regulate HSCC proliferation, invasion, and metastasis $(9,10)$. lncRNAs have been reported to modulate multiple signaling pathways in tumorigenesis and metastasis, such as VEGFA signaling, Wnt/beta-catenin signaling, and epithelial-mesenchymal transition (EMT) (11-13). RP11-156L14.1 is a novel lncRNA that has been identified in cutaneous anaplastic large cell lymphoma (14). It has also been demonstrated to be highly expressed in various cancers, including HSCC (15). However, the expression profile and functional role of RP-11-156L14.1 in HSCC are not clear.

MicroRNAs (miRNAs) are small non-coding RNAs, which can post-transcriptionally regulate target gene expression in tumor progression and metastasis (16). miRNAs including miR-489, miR-451a, and miR-504 have been demonstrated to serve as tumor suppressors in $\operatorname{HSCC}(2,17,18)$. Notably, lncRNAs can sponge miRNAs and function as competing endogenous RNAs (ceRNAs) (19). Multiple studies have described the IncRNA-miRNA-mRNA axis in HSCC $(11,20,21)$. Kolenda et al reported that lncRNA ZFAS1 regulated the HSCC cell phenotype via miR-150-5p (22). Thus, understanding the interplay between lncRNA and 
miRNA in HSCC may lead to new therapeutic strategies for HSCC.

In the present study, a novel lncRNA RP11-156L14.1 was identified that was highly expressed in HSCC tissues and cell lines. Knockdown of RP11-156L14.1 inhibited HSCC cell proliferation, migration, and invasion in vitro. Furthermore, knockdown of RP11-156L14.1 suppressed HSCC tumor development in vivo. Mechanistically, RP11-156L14.1 directly interacted with miR-548ao-3p as a ceRNA and regulated the expression of downstream targets of the signal sequence receptor subunit 1 (SSR1). In summary, these findings indicated that the 1ncRNA RP11-156L14.1/miR-548ao-3p/SSR1 axis may be a new potential biomarker in the clinical treatment of HSCC.

\section{Materials and methods}

Clinical specimens. Thirty pairs of HSCC tissues and the adjacent normal tissues were obtained from patients (aged, 33-65 years; 15 male and 15 female patients) who underwent surgical treatment at the Second Affiliated Hospital of Xi'an Jiaotong University. All patients underwent hypopharyngeal tumor resection plus ipsilateral modified neck dissection. None of the patients had received chemoradiotherapy or biotherapy before surgery. Before undergoing surgery, all patients provided written informed consent for their tissues to be used in the present study. The Ethics Committee of the Second Affiliated Hospital of Xi'an Jiaotong University approved this study. All tissues were snap frozen in liquid nitrogen before sample procession.

Cell culture. The HSCC cell lines FaDu (derived from a primary lesion of hypopharyngeal SCC), SAS (derived from a primary lesion of tongue SCC), and HSC3 (derived from lymph node metastasis of tongue SCC) were obtained from American Type Culture Collection (ATCC). The normal epithelial cell line Nthy-ori3-1 was maintained at our laboratory. All cell lines were cultured in DMEM with $10 \%$ fetal bovine serum (FBS; both from Gibco; Thermo Fisher Scientific, Inc.) and 1\% penicillin-streptomycin in a humidified atmosphere containing $5 \% \mathrm{CO}_{2}$ at $37^{\circ} \mathrm{C}$. Mycoplasma contamination was not detected in any cell line.

Transfection. Briefly, the cells were seeded onto 6- or 96 -well plates. When cell confluency reached $\sim 60-70 \%$, the medium was changed to DMEM without $10 \%$ FBS, and the transfection was conducted using Lipofectamine ${ }^{\mathrm{TM}} 3000$ (Invitrogen; Thermo Fisher Scientific, Inc.). The different transfection groups were as follows: i) empty vector group and pcDNA3.1-RP11-156L14.1 group; ii) negative control (NC) group and si-RP11-156L14.1-1/2/3 groups; iii) NC+miR-Ctrl group, pcDNA3.1-RP11-156L14.1+ miR-Ctrl group, NC+miR-548ao-3p mimic group, and pcDNA3.1-RP11-156L 14.1+miR-548ao-3p mimic group; iv) si-NC+miR-Ctrl group, si-RP11-156L14.1+miR-Ctrl group, si-NC+miR-548ao-3p group, and si-RP11-156L14.1+miR-548ao-3p mimic group; v) si-NC+miR-548ao-3p inhibitor NC group, si-RP11-156L14.1+miR-548ao-3p inhibitor NC group, and si-RP11-156L14.1+miR-548ao-3p inhibitor group. The cells were harvested at the indicated time-point $(48 \mathrm{~h})$ for further experimentation. The FaDu cells were transfected with RP11-156L14.1-knockdown vector or control vector, with or without miR-548ao-3p inhibitors.

Reverse transcription-quantitative PCR (RT-qPCR). Total RNA was purified from patient tissues or cultured cells using TRIzol (Invitrogen; Thermo Fisher Scientific, Inc.). cDNA was obtained through reverse transcription using a PrimeScript RT reagent Kit (Takara Bio Inc.). Real-time quantitative PCR was performed using a SYBR PrimeScript ${ }^{\mathrm{TM}}$ PLUS Kit (Takara Bio, Inc.) to detect the expression levels of IncRNA-RP11-156L14.1, miR-548ao-3p, and SSR1. GAPDH or U6 was used as the endogenous control to normalize the expression level through $2^{-\Delta \Delta \mathrm{Cq}}$ method (23). Thermal conditions of PCR reactions were: $95^{\circ} \mathrm{C}$ for $1 \mathrm{~min}$, and then $12 \mathrm{sec}$ at $95^{\circ} \mathrm{C}$ and $32 \mathrm{sec}$ at $57^{\circ} \mathrm{C}$ for 40 cycles. The primers used were as follows: RP11-156L14.1 forward, 5'-AAAACCACC AGCCCTTTCTCATCC-3' (forward) and reverse, 5'-TAG CCT TCC TCC TGA TCT GCC AAG-3'; miR-548ao-3p, 5'-CGCAAAGACCGTGACTACTTTTGCA-3' (universal miRNA reverse primer: cat. no. B532451-0020; Sangon Biotech Co., Ltd.); SSR1 forward, 5'-GGAGCCGCCGAG AGCCTTAG-3' and reverse, 5'-ACGAGTAAGAGAAGCAGC AGCAAG-3'; GAPDH forward, 5'-GGGAGCCAAAAGGGT CAT-3' and reverse, 5'-GAGTCCTTCCACGATACCAA-3'. All assays were performed independently in triplicate.

Cell proliferation assays. Cells were seeded into 96-well plates with a density of $2 \times 10^{4}$ cells/well. After transfection, the cells were cultured for the indicated time-points $(0,24,48$ and $72 \mathrm{~h})$, and then cell proliferation ability was evaluated by a CCK- 8 assay (Dojindo Molecular Technologies, Inc.) following the manufacturer's protocol. At each time-point, $10 \mu \mathrm{l}$ of CCK-8 reagent was added into each well. Cells were incubated at $37^{\circ} \mathrm{C}$ subsequently for $2 \mathrm{~h}$. Against a background control, the sample absorbance was tested at $450 \mathrm{~nm}$ via a microplate reader (Bio-Rad Laboratories, Inc.). EdU staining was performed to evaluate DNA synthesis in proliferating cells with an EdU assay Kit (Invitrogen; Thermo Fisher Scientific, Inc.) following the manufacturer's instructions. After transfection, cells were cultured for $48 \mathrm{~h}$, fixed with $4 \%$ paraformaldehyde and permeabilized by $0.3 \%$ Triton X-100. Then cells were incubated with $10 \mu \mathrm{M}$ EdU for $2 \mathrm{~h}$, and cell nuclei were stained with DAPI $(5 \mu \mathrm{g} / \mathrm{ml})$. The number of EdU-positive cells was counted under a light microscope in five random fields (Olympus Corporation; magnification, x10). For colony formation assay, cells were seeded into 6-well plates at a density of 500 cells per well and cultured for 10 days. Then the cell colonies were fixed with methanol for $10 \mathrm{~min}$ at room temperature, stained with $0.1 \%$ crystal violet at room temperature for $15 \mathrm{~min}$, and then counted under the inverted light microscope (Olympus Corporation; magnification, x10). All assays were performed independently in triplicate.

Cell cycle analysis. Cells $\left(2 \times 10^{3}\right)$ were fixed with $70 \%$ ethanol at $4^{\circ} \mathrm{C}$ overnight. The fixed cells were treated with ribonuclease A $(20 \mu \mathrm{g} / \mathrm{ml}$; Sigma-Aldrich; Merck KGaA) and incubated with $50 \mu \mathrm{g} / \mathrm{ml}$ propidium iodide (Sigma-Aldrich; Merck KGaA) for $30 \mathrm{~min}$ at $37^{\circ} \mathrm{C}$. Then, the populations in G2-M, S, and G0-G1 phases were determined by flow cytometric analysis 
(BD Biosciences). All assays were performed independently in triplicate.

Wound healing assay. After transfection, Ntrhy-ori3-1 or $\mathrm{FaDu}$ cells $\left(5 \times 10^{5}\right)$ were seeded into 6 -well plates and cultured until $90 \%$ confluency. Wounds were stimulated by scratching with a $200-\mu 1$ sterile pipette tip. The floating cells were washed away with PBS. Cell migration was monitored by examining the closure of the wound at 0 and $48 \mathrm{~h}$ under an inverted optical microscope (Olympus Corporation; magnification, x10). All assays were performed independently in triplicate.

Transwell assay. Cell invasion was analyzed using a 24-well Transwell chamber (Costar, Inc.) with Matrigel-coated membranes. Ntrhy-ori3-1 or FaDu cells were seeded into the upper chamber in FBS-free DMEM, and $500 \mu \mathrm{l}$ DMEM medium with $10 \%$ FBS was added to the bottom chamber. After $48 \mathrm{~h}$, the invading cells in the bottom chamber were fixed with formaldehyde (3.7\% in PBS) for $5 \mathrm{~min}$ at room temperature and stained with $0.1 \%$ crystal violet at room temperature for $15 \mathrm{~min}$ and then counted under the inverted light microscope (Olympus Corporation; magnification, x10). All assays were performed independently in triplicate.

Western blotting. Cells were lysed using a Protein Extraction kit according to the manufacturer's protocols (Beyotime Institute of Biotechnology). RIPA buffer (Beijing Solarbio Science and Technology Co., Ltd.) was used to extract total protein from the cultured cells. A BCA protein assay kit (Thermo Fisher Scientific, Inc.) was used to quantify the proteins. Equal amounts of protein samples $(30 \mu \mathrm{g})$ were separated with $10 \%$ SDS-PAGE and electro-transferred onto PVDF membranes (EMD Millipore). The membranes were blocked with 5\% non-fat milk/PBS for $1 \mathrm{~h}$ at room temperature and then incubated by primary antibodies: Anti-E-cadherin $(1: 2,000$; product code ab1416; Abcam), anti-N-cadherin (1:1,000; product code ab76057; Abcam), anti-vimentin (1:2,000; product code ab8978; Abcam), anti-SSR1 (1:1,000; product no. 12009; Cell Signaling Technology, Inc.), anti-Ki67 (1:1,000; product code ab92742; Abcam), and anti- $\beta$-actin (1:5,000; product code ab179467; Abcam) at $4^{\circ} \mathrm{C}$ overnight. After the membranes were washed with PBST three times, they were further incubated with secondary antibodies: Anti-mouse IgG, HRP-linked and anti-rabbit IgG, HRP-linked (both 1:3,000; cat. nos. 7076 and 7074, repectively; Cell Signaling Technology, Inc.) for $2 \mathrm{~h}$ at room temperature. The membranes were developed using the ECL system (EMD Millipore). All assays were performed independently in triplicate and the desitometric analysis was performed using ImageJ (1.49p; National Institutes of Health).

Luciferasereporterassay.Aluciferasereportervectorcontaining the 3'-UTR of RP11-156L14.1 with the predicted miR-548ao-3p binding site was constructed (pGL3-RP11-156L14.1-wild-type and pGL3-RP11-156L14.1-Mut). Similarly, luciferase reporter vectors containing the 3'-UTR of SSR1-wild-type and SSR1-mutated were constructed. All reporter vectors used the basic pGL3-Luc vector (Promega) as a backbone vector. Cells were co-transfected with luciferase reporter plasmids and control Renilla luciferase vector (Promega, USA) using Lipofectamine $^{\mathrm{TM}} 3000$ (Invitrogen; Thermo Fisher Scientific,
Inc.), and the relative luciferase activities were analyzed $48 \mathrm{~h}$ later using a dual-luciferase reporter assay kit (Promega Corporation). All assays were performed independently in triplicate.

Cytoplasmic and nuclear fractions. To determine the subcellular localization of RP11-156L14.1, cytoplasmic and nuclear fractions of FaDu or SAS cells were prepared using a PARIS Kit (Life Technologies; Thermo Fisher Scientific, Inc.) following the manufacturer's protocol. The fractions were subjected to subsequent RT-qPCR analysis. GAPDH and U6 were used as internal controls for the cytoplasm and nucleus, respectively. All assays were performed independently in triplicate.

RNA immunoprecipitation (RIP) assay. An RNA immunoprecipitation assay was performed by Imprint RNA immunoprecipitation kit (Sigma-Aldrich; Merck KGaA) referring to the recommended protocols of the manufacturer. Firstly, IgG-induced chondrocytes were collected and resuspended in RIP lysis bufer (Beijing Solarbio Science and Technology Co., Ltd.), subsequently centrifuged at $12,000 \mathrm{x}$ g for $5 \mathrm{~min}$. Ten, cell lysates were incubated with anti-Argonaute2 (anti-Ago2) or anti-IgG (negative control) overnight at $4^{\circ} \mathrm{C}$, followed by the addition of Protein A magnetic beads (cat. no. 73778; Cell Signaling Technology) to obtain the immunoprecipitation complex. Total RNA was isolated using GenElute ${ }^{\mathrm{TM}}$ Total RNA Purifcation Kit (Sigma-Aldrich; Merck KGaA). Lastly, the relative enrichment of RP11-156L14.1 and miR-548ao-3p were determined by RT-qPCR analysis. All assays were performed independently in triplicate.

Tumor xenograft model. The posterior flanks of the BALB/c nude mice (male, 6 weeks old, $n=15$ ) were subcutaneously injected with $\mathrm{FaDu}$ cells $\left(2 \times 10^{7}\right)$ transfected with sh-RP11-156L14.1 or the negative control. The animals were monitored daily and the following criteria for humane endpoint was used: Severe tumor burden (more than $20 \mathrm{~mm}$ in diameter), difficulty breathing, significant body-weight loss, and clinical signs such as prostration, hypothermia, and significant abdominal distension. Tumor volumes were examined every four days, the maximum tumor diameter observed in this study was $1.4 \mathrm{~cm}$. On day 13 after inoculation, the mice were euthanized by $\mathrm{CO}_{2}$ inhalation $\left(\mathrm{CO}_{2}\right.$ flow rate: $10 \%$ of cage volume) and the death of animals were confirmed by cessation of heartbeat. Tumor xenografts were harvested, photographed, and weighed. The maximum weight loss of all the mice used in this study was $6.3 \%$ of initial body weight. The maximum tumor weight/body weight ratio observed was $8.6 \%$. The animal experiments were conducted under the protocol approval of the Ethics Committee of Animal Welfare of the Second Affiliated Hospital of Xi'an Jiaotong University.

Target prediction. Potential target miRNAs of RP11-156L14.1 were predicted by the Lncbase v.2 (http://carolina.imis.athena innovation.gr/diana_tools/web/index.php? $r=\operatorname{lncbasev} 2 /$ index). The target genes of miR-548ao-3p were predicted using three bioinformatics algorithms: TargetScan human 7.2 (http://www. targetscan.org/vert_72/), miRDB (http://www.mirdb.org) and microT-CDS v5.0 (http://diana.imis.athena-innovation. gr/DianaTools/index.php?r=microT_CDS/index). 
A

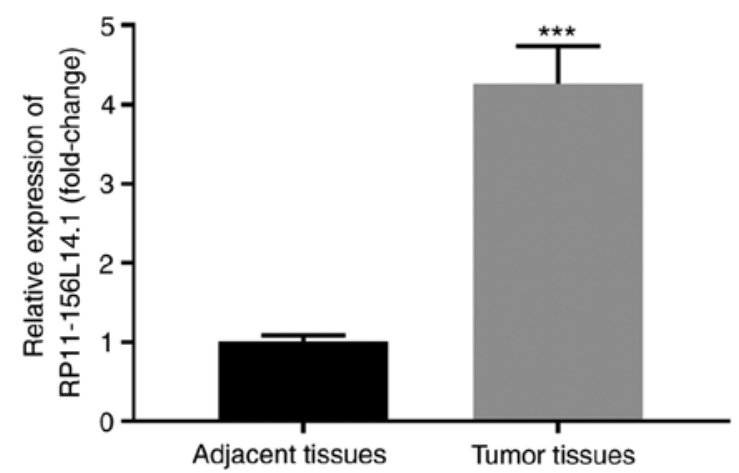

B

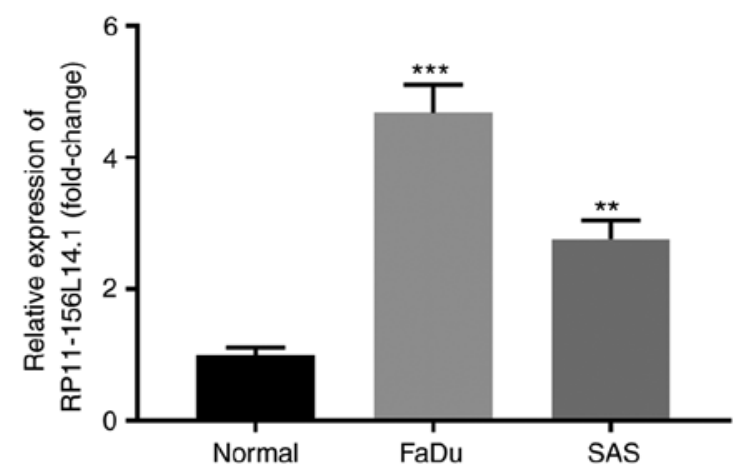

Figure 1. RP11-156L14.1 is highly expressed in HSCC tissues and cell lines. (A) The relative expression levels of RP11-156L14.1 in 30 paired HSCC tumor tissues and adjacent non-tumor tissues were analyzed by RT-qPCR. (B) The relative expression levels of RP11-156L14.1 in HSCC cell lines (FaDu and SAS) and normal tissues were measured by RT-qPCR. ${ }^{* *} \mathrm{P}<0.01,{ }^{* * *} \mathrm{P}<0.001$. HSCC, hypopharyngeal squamous cell carcinoma; RT-qPCR, reverse transcription-quantitative PCR.

Table I. Association of clinicopathological features with lncRNA RP11-156L14.1 expression.

\section{RP11-156L14.1 expression}

Characteristics Low $(n=15)$ High $(n=15) \quad$ P-value

\begin{tabular}{lrrr}
\hline $\begin{array}{l}\text { Age (years) } \\
\leq 60\end{array}$ & 7 & 9 & 0.4642 \\
$>60$ & 8 & 6 & \\
Sex & & & 0.2733 \\
$\quad$ Male & 9 & 6 & \\
$\quad$ Female & 6 & 9 & \\
TNM stage & & & 0.0034 \\
I+II & 11 & 3 & \\
III+IV & 4 & 12 & \\
Lymph node metastasis & & & 0.0281 \\
$\quad$ Negative & 10 & 4 & \\
Positive & 5 & 11 & \\
\hline
\end{tabular}

Statistical analysis. Statistical analyses were calculated using GraphPad Prism 7.0 software (GraphPad Software, Inc.), and the results are presented as the mean \pm SD. Statistical comparisons among multiple groups were analyzed by one-way analysis of variance (ANOVA) followed by Tukey's post hoc tests, and $\mathrm{P}<0.05$ was considered to indicate a statistically significant difference.

\section{Results}

RP11-156L14.1 is highly expressed in HSCC tissues and cell lines. To investigate the expression pattern of lncRNA RP11-156L14.1 in HSCC, RP11-156L14.1 expression was assessed in 30 paired HSCC tumor tissues and adjacent normal tissues. The RP11-156L14.1 mRNA level was significantly higher in tumor tissues compared with that in the adjacent normal tissues (Fig. 1A). In addition, the expression levels of RP11-156L14.1 in the HSCC cell lines FaDu and SAS were also higher in comparison with those in normal tissues (Fig. 1B). High expression of RP11-156L14.1 was significantly associated with advanced TNM stages and lymph node metastasis in HSCC (Table I).

Knockdown of RP11-156L14.1 inhibits cell proliferation and the cell cycle in HSCC cell lines. To explore the function of RP11-156L14.1, RNA interference studies involving RP11-156L14.1 knockdown in HSCC cell lines were employed. FaDu cells were transfected with si-Control or si-RP11-156L14.1-1/2/3, and the knockdown efficiency was evaluated by qPCR (Fig. 2A). The most efficient si-RP11-156L14.1-2 was used in the subsequent experiments. The CCK-8 assay demonstrated that cell proliferation was significantly suppressed in SAS and FaDu cells transfected with si-RP11-156L14.1 compared with that in control-transfected cells (Fig. 2B and C). Furthermore, EDU incorporation assays and colony formation assays found that DNA synthesis and colony formation capabilities, respectively, were decreased after RP11-156L14.1 knockdown in SAS and FaDu cells (Fig. 2D and E). Cell cycle analysis was performed on both cell lines using propidium iodide staining. As revealed in Fig. 2F, the fraction of cells in the $\mathrm{S}$ phase was significantly reduced in SAS and FaDu cells transfected with si-RP11-156L14.1 compared with that in cells transfected with the control vector.

Knockdown of RP11-156L14.1 inhibits the migration, invasion, and EMT in HSCC cells. The function of RP11-156L14.1 on HSCC metastasis was further evaluated. As demonstrated by the wound healing assay, knockdown of RP11-156L14.1 decreased the wound healing capabilities of SAS and $\mathrm{FaDu}$ cells (Fig. 3A and B). It was also determined that knockdown of RP11-156L14.1 in SAS or FaDu cells inhibited the cell metastasis phenotype since the migration and invasion abilities were decreased (Fig. 3C and D). Since tumor metastasis has been revealed to be closely associated to cell-cell adhesion and EMT (24), the levels of EMT-related proteins after RP11-156L14.1 knockdown were examined. Notably, the results revealed that knockdown of RP11-156L14.1 enhanced E-cadherin expression and inhibited $\mathrm{N}$-cadherin and vimentin expression in SAS and FaDu cells (Fig. 3E). Decreased 
A

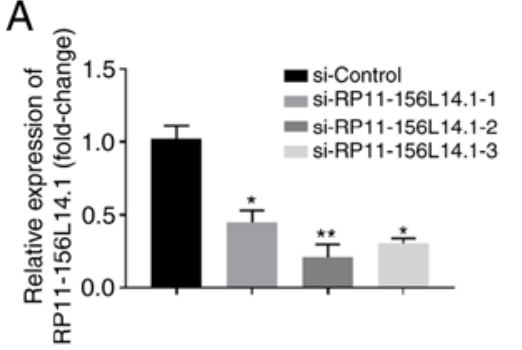

B

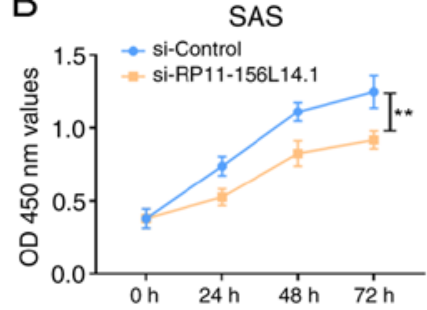

D
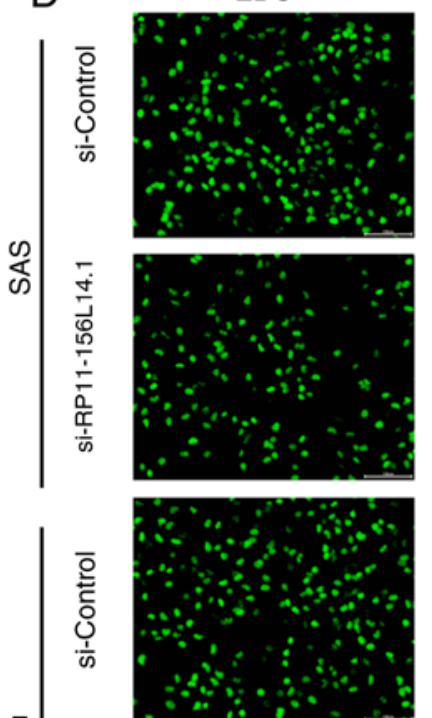

芯

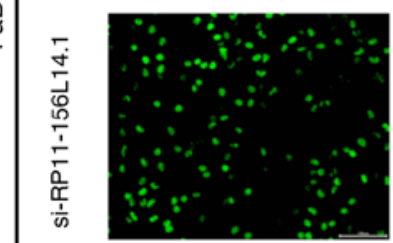

$\mathrm{F}$

si-Control

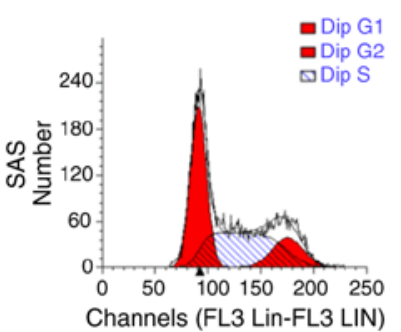

si-Control

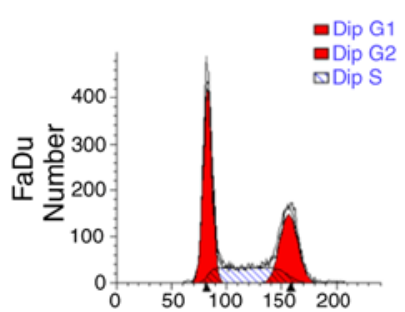

Channels (FL3 Lin-FL3 LIN)
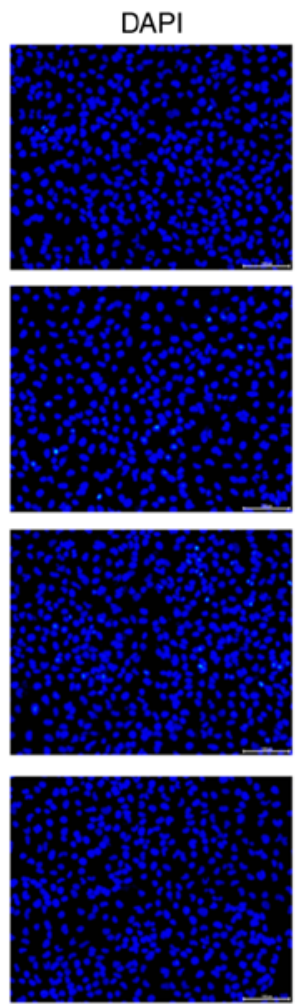

si-RP11-156L14.1
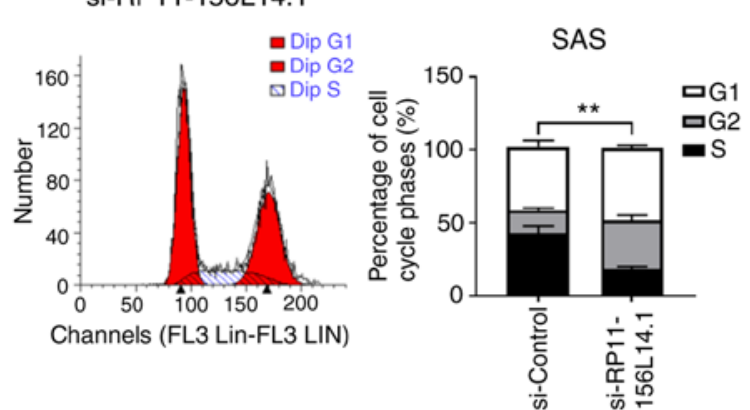

si-RP11-156L14.1

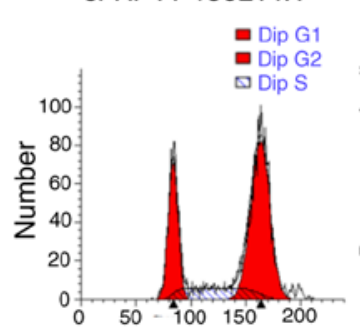

Channels (FL3 Lin-FL3 LIN)
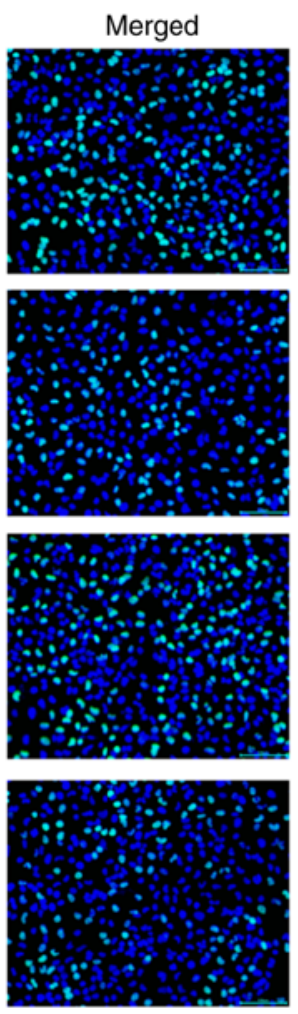

\section{$E$}

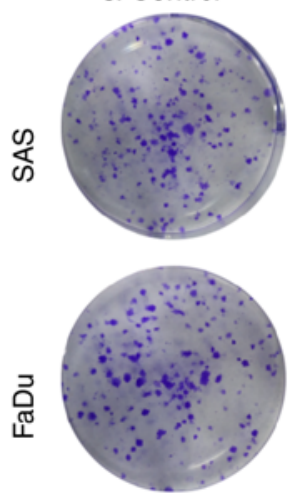

si-RP11-156L14.1
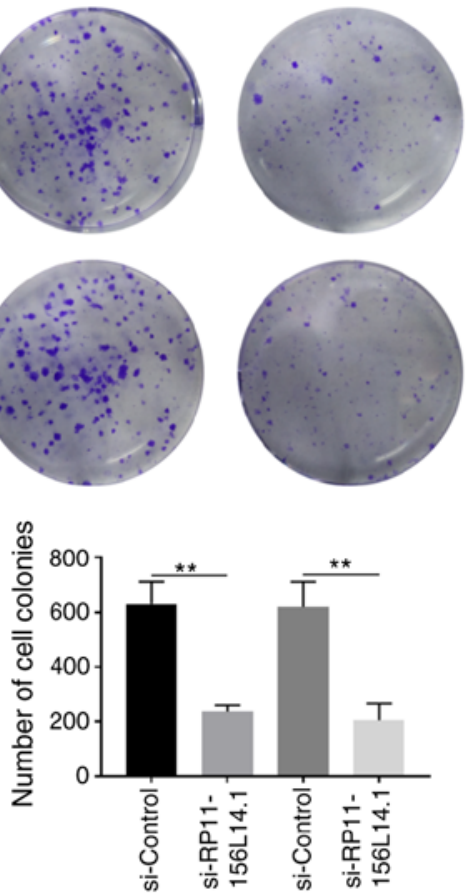

Figure 2. Knockdown of lncRNA RP11-156L14.1 inhibits cell proliferation and the cell cycle in HSCC cell lines. (A) FaDu cells were transfected with the control vector (si-Control) or the RP11-156L14.1-knockdown vector (si-RP11-156L14.1-1/2/3). The knockdown efficiency was evaluated by RT-qPCR $48 \mathrm{~h}$ later SAS or FaDu cells were transfected with si-Control or si-RP11-156L14.1. (B and C) Cell proliferation was determined with the CCK-8 assay at the indicated time-points. (D) DNA synthesis was measured by EdU staining. (E) A colony formation assay was conducted to evaluate SAS and FaDu cell colony formation capabilities. (F) Flow cytometric analysis of the cell cycle in SAS or FaDu cells stained with propidium iodide. ${ }^{*} \mathrm{P}<0.05,{ }^{* * *} \mathrm{P}<0.01$. lncRNA, long non-coding RNA; HSCC, hypopharyngeal squamous cell carcinoma; RT-qPCR, reverse transcription-quantitative PCR; CCK-8, Cell Counting Kit-8. 

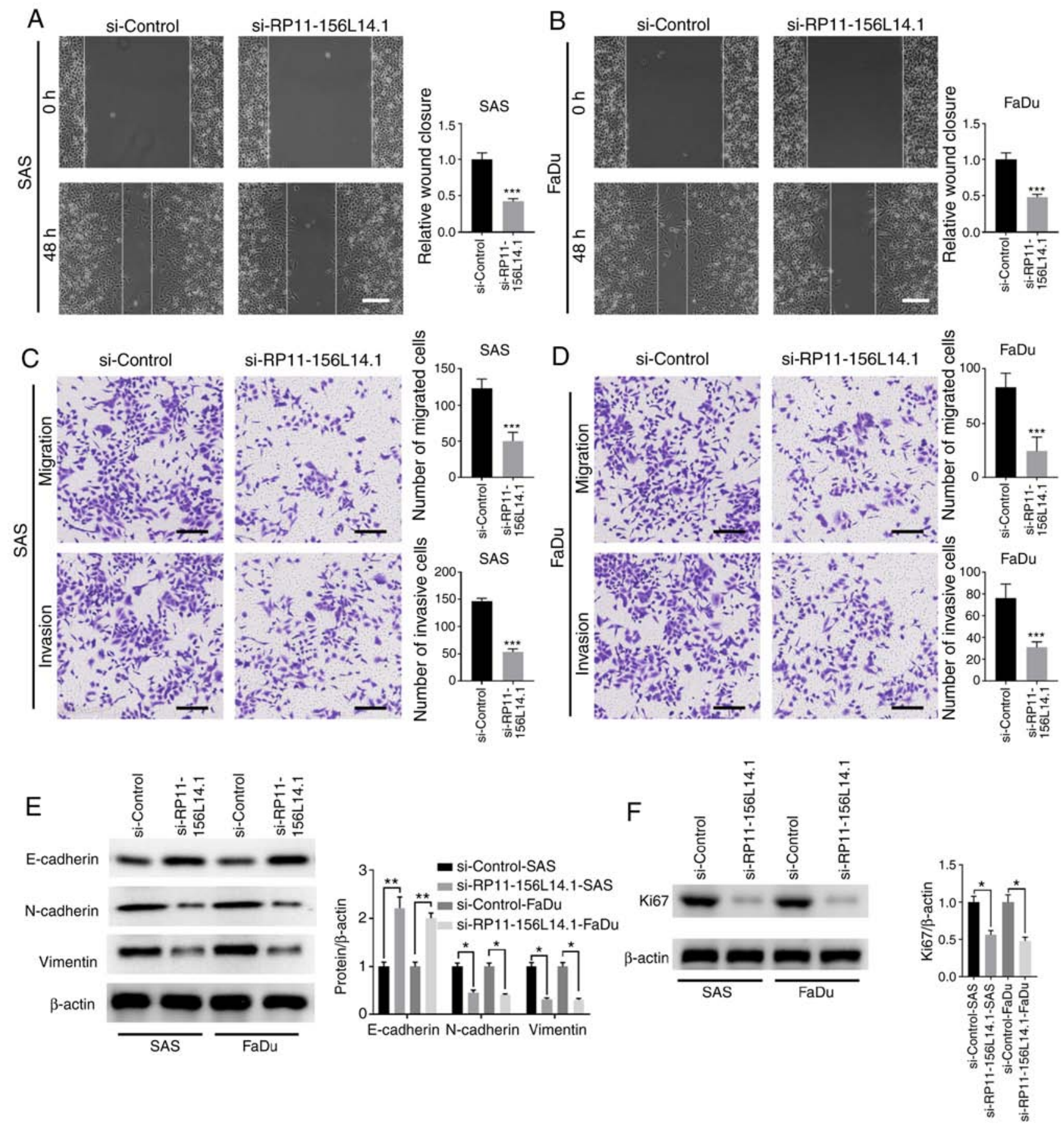

Figure 3. Knockdown of lncRNA RP11-156L14.1 inhibits the migration, invasion, and EMT in HSCC cells. SAS or FaDu cells were transfected with si-Control or si-RP11-156L14.1. (A and B) Cell migration capability was analyzed by wound healing assay. (C and D) A Transwell assay was performed to assess cell migration and invasion in SAS and FaDu cells. (E) EMT-related proteins E-cadherin, N-cadherin, and vimentin and (F) proliferation-marker Ki67 were determined by western blotting in SAS and FaDu cells. $\beta$-actin was used as an internal control. The experiment was repeated three times, and the representative blot images are presented. ${ }^{*} \mathrm{P}<0.05,{ }^{* *} \mathrm{P}<0.01,{ }^{* * *} \mathrm{P}<0.001$. IncRNA, long non-coding RNA; EMT, epithelial-mesenchymal transition; HSCC, hypopharyngeal squamous cell carcinoma.

E-cadherin expression and enhanced vimentin expression may be associated with the increased migration and invasion of HSCC cells. Knockdown of RP11-156L14.1 was consistently revealed to inhibit the protein expression of the proliferation marker Ki67 in SAS and FaDu cells (Fig. 3F).

RP11-156L14.1 directly binds to miR-548ao-3p in HSCC cell lines. To investigate the potential mechanism of RP11-156L14.1 in HSCC, subcellular fractionation was performed, and lncRNA
RP11-156L14.1 was mainly located in the cytoplasm, indicating that RP11-156L14.1 may be involved in the post-transcriptional regulation of target genes (Fig. 4A). Bioinformatics analyses were performed using the online tools LncbaseV2 and RegRNA. Multiple miRNAs were predicted to interact with RP11-156L14.1 (miR-580-3p, miR-875-3p, miR-548ao-3p, miR-664b-3p, miR-660-3p, and miR-373-5p). A luciferase reporter assay was performed to verify the interaction between miRNAs and RP11-156L14.1, whereas miR-548ao-3p mimics 
A

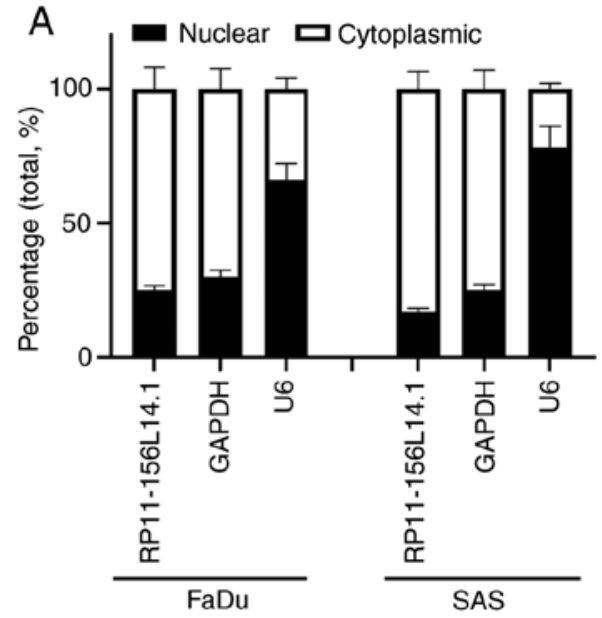

C

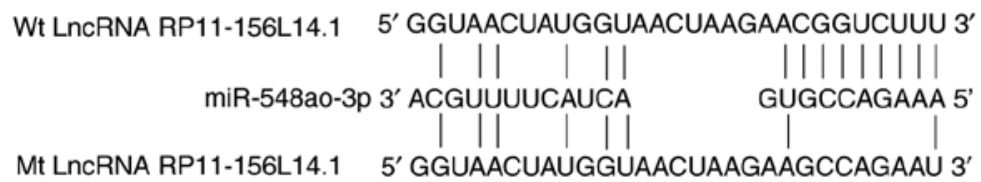

Mt LncRNA RP11-156L14.1 5' GGUAACUAUGGUAACUAAGAAGCCAGAAU 3'
B
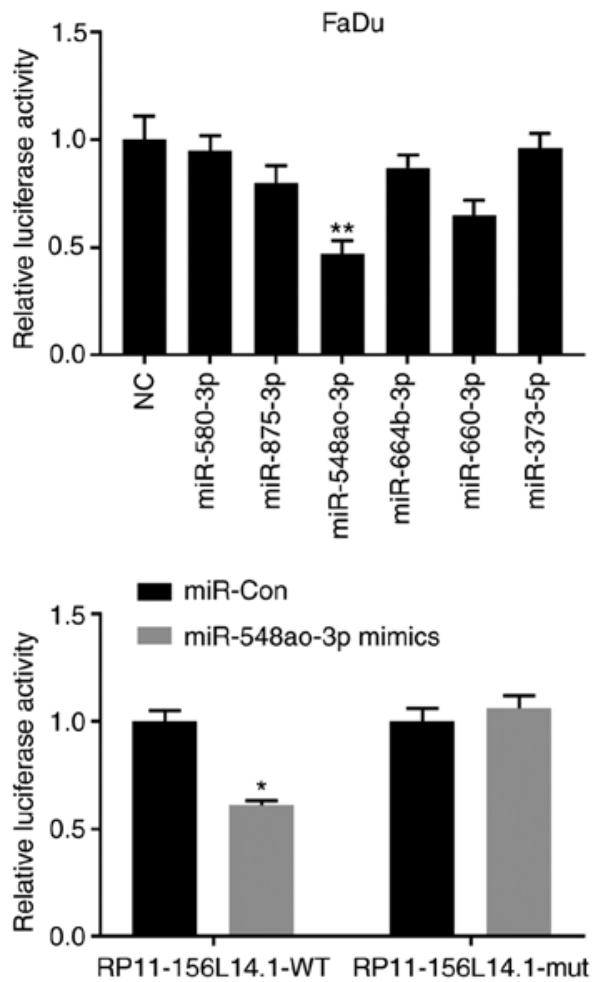

$\mathrm{E}$

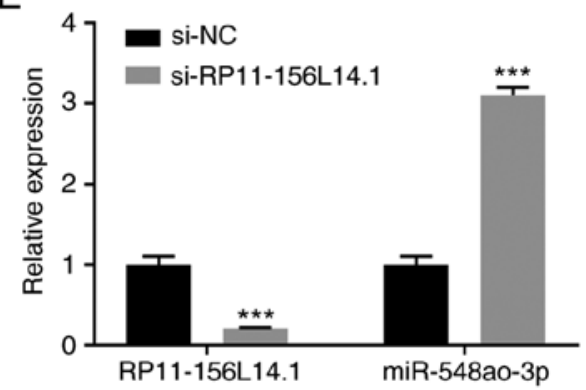

G

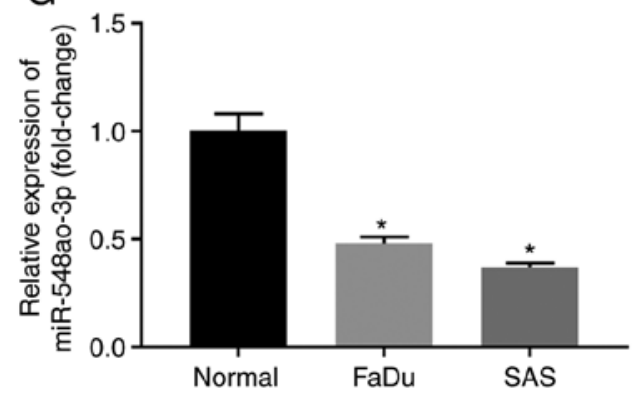

Figure 4. IncRNA RP11-156L14.1 directly binds to miR-548ao-3p in HSCC cell lines. (A) A subcellular fractionation assay was performed in FaDu or SAS cells. The relative expression levels of RP11-156L14.1, GAPDH, and U6 in the cytoplasm or nucleus were analyzed by qPCR. (B) FaDu cells were transfected with a luciferase reporter containing the 3'-UTR of RP11-156L14.1, in combination with different miRNA mimics or a negative control. The relative luciferase activity was analyzed $48 \mathrm{~h}$ later. (C) Bioinformatics analysis predicted putative binding sequences between wt RP11-156L14.1 and miR-548ao-3p. The mutated RP-11-154L14.1 sequences are listed. 293 cells were transfected with miR-Con or miR-548ao-3p mimics, in combination with a reporter vector containing RP11-156L14.1-wt or RP11-156L14.1-mut sequences. Relative luciferase activity was measured $48 \mathrm{~h}$ later. (D) Ago2 immunoprecipitation experiments were performed in FaDu cells, and IgG was used as a control. The relative expression of RP11-156L14.1 or miR-548ao-3p was determined by qPCR. (E) FaDu cells were transfected with RP11-156L14.1 knockdown vector, along with si-NC control vectors. The relative expression of RP11-156L14.1 or miR-548ao-3p was determined by qPCR. (F) The relative expression of miR-548ao-3p in HSCC tumor tissues and adjacent non-tumor tissues was determined by qPCR. (G) The relative expression of miR-548ao-3p in HSCC cell lines and normal tissues was determined by qPCR. ${ }^{*} \mathrm{P}<0.05,{ }^{* *} \mathrm{P}<0.01,{ }^{* * *} \mathrm{P}<0.001$. lncRNA, long non-coding RNA; HSCC, hypopharyngeal squamous cell carcinoma; wt, wild-type; qPCR, quantitative PCR.

significantly inhibited the luciferase activity in $\mathrm{FaDu}$ cells transfected with a reporter vector containing the $3^{\prime}$-UTR of RP11-156L14.1 (Fig. 4B). RP11-156L14.1 exhibited putative binding sequences with miR-548ao-3p (Fig. 4C). The luciferase reporter assay demonstrated that miR-548ao-3p mimics could inhibit the relative luciferase activity in 293 cells with reporter 
A

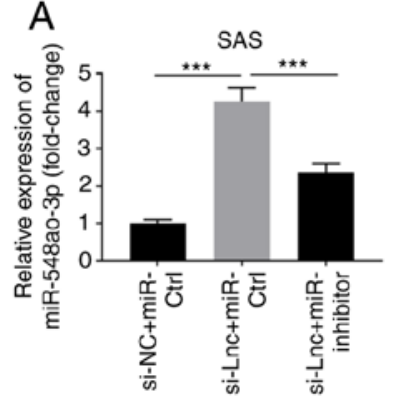

$\mathrm{E}$
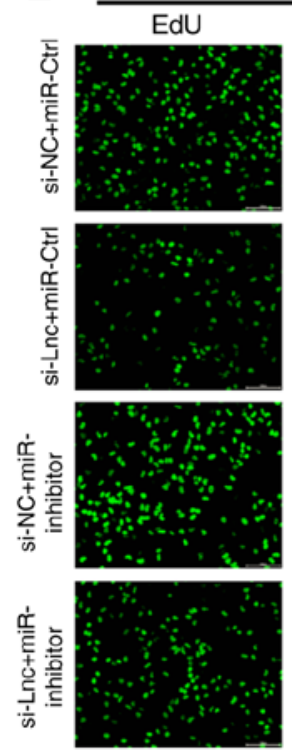

B

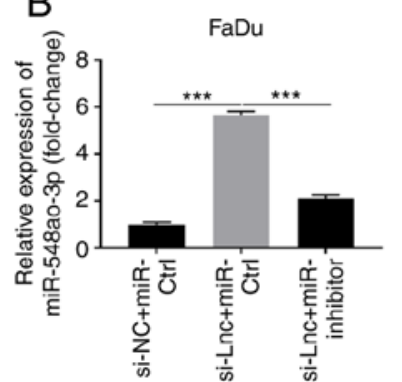

C

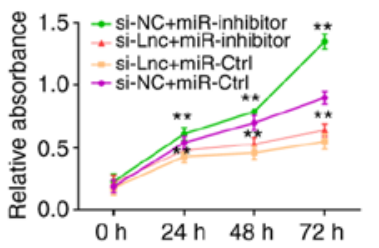

D

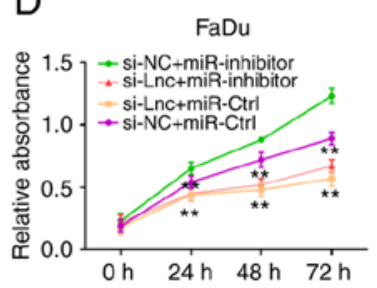

$$
\text { 容 }
$$
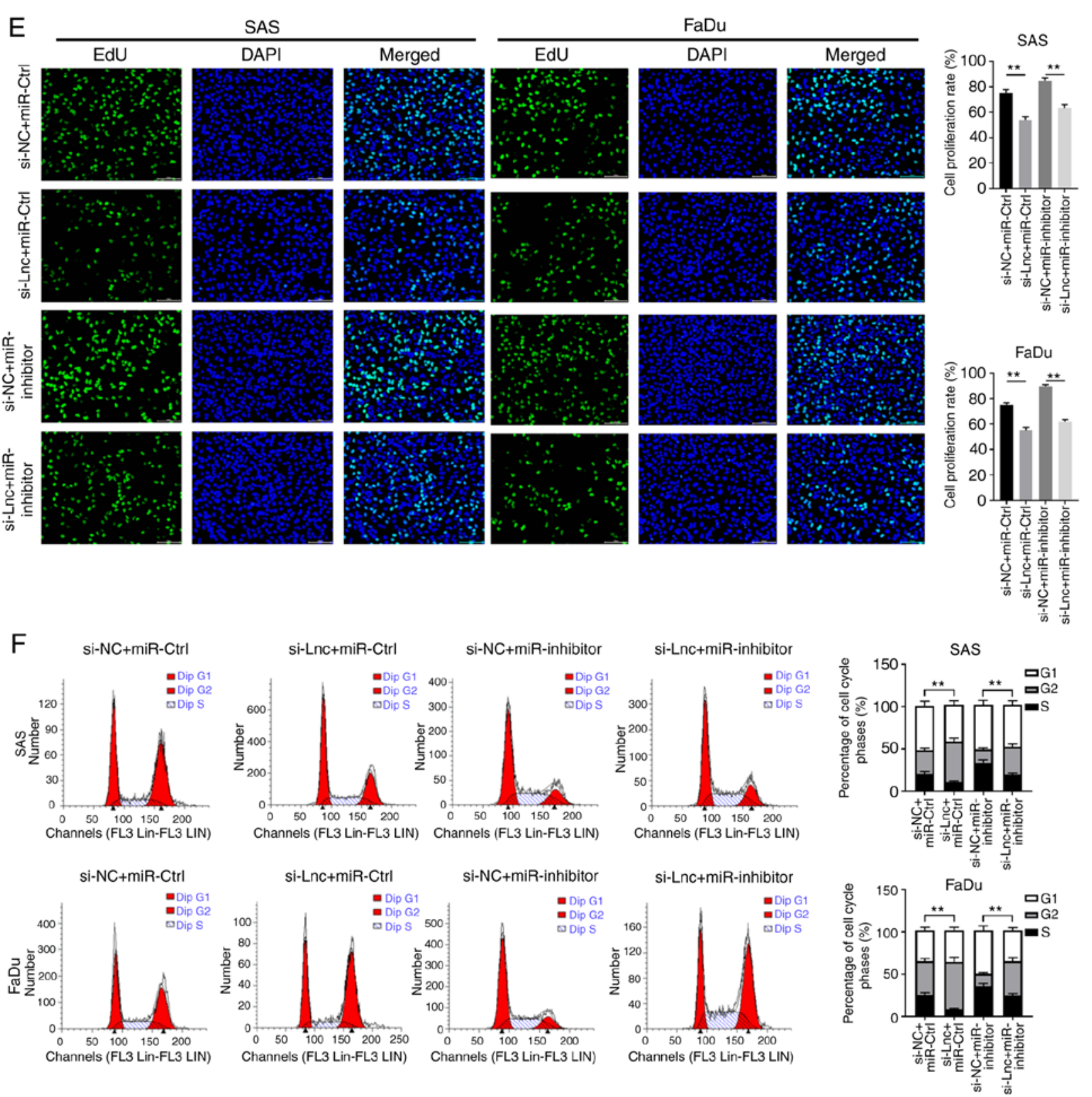

Figure 5. RP11-156L14.1 promotes cell proliferation and the cell cycle via miR-548ao-3p in HSCC cells. SAS or FaDu cells were transfected with si-NC+miR-Ctrl, si-RP11-156L14.1+miR-Ctrl, or si-RP11-156L14.1+miR-548ao-3p inhibitor. (A and B) The relative expression of miR-548ao-3p was assessed by RT-qPCR $48 \mathrm{~h}$ later. SAS or FaDu cells were transfected with si-NC+miR-Ctrl, si-RP11-156L14.1+miR-Ctrl, si-NC+miR-548ao-3p inhibitor, or si-RP11-156L14.1+miR-548ao-3p inhibitor. (C and D) Cell proliferation was determined with the CCK-8 assay at the indicated time-points. (E) DNA synthesis was measured by EdU staining. (F) Flow cytometric analyses of the cell cycle in SAS or FaDu cells stained with propidium iodide. ${ }^{* *} \mathrm{P}<0.01{ }^{* * * *} \mathrm{P}<0.001$. HSCC, hypopharyngeal squamous cell carcinoma; RT-qPCR, reverse transcription-quantitative PCR; CCK-8, Cell Counting Kit-8.

vectors containing wild-type RP11-156L14.1 sequences but not in those with mutated RP11-156L14.1 sequences (Fig. 4C). Ago2 immunoprecipitation experiments revealed that RP11-156L14.1 was identified as a bona fide miR-548ao-3p target in $\mathrm{FaDu}$ cells (Fig. 4D). Moreover, the present study also demonstrated that knockdown of RP11-156L14.1 enhanced miR-548ao-3p 

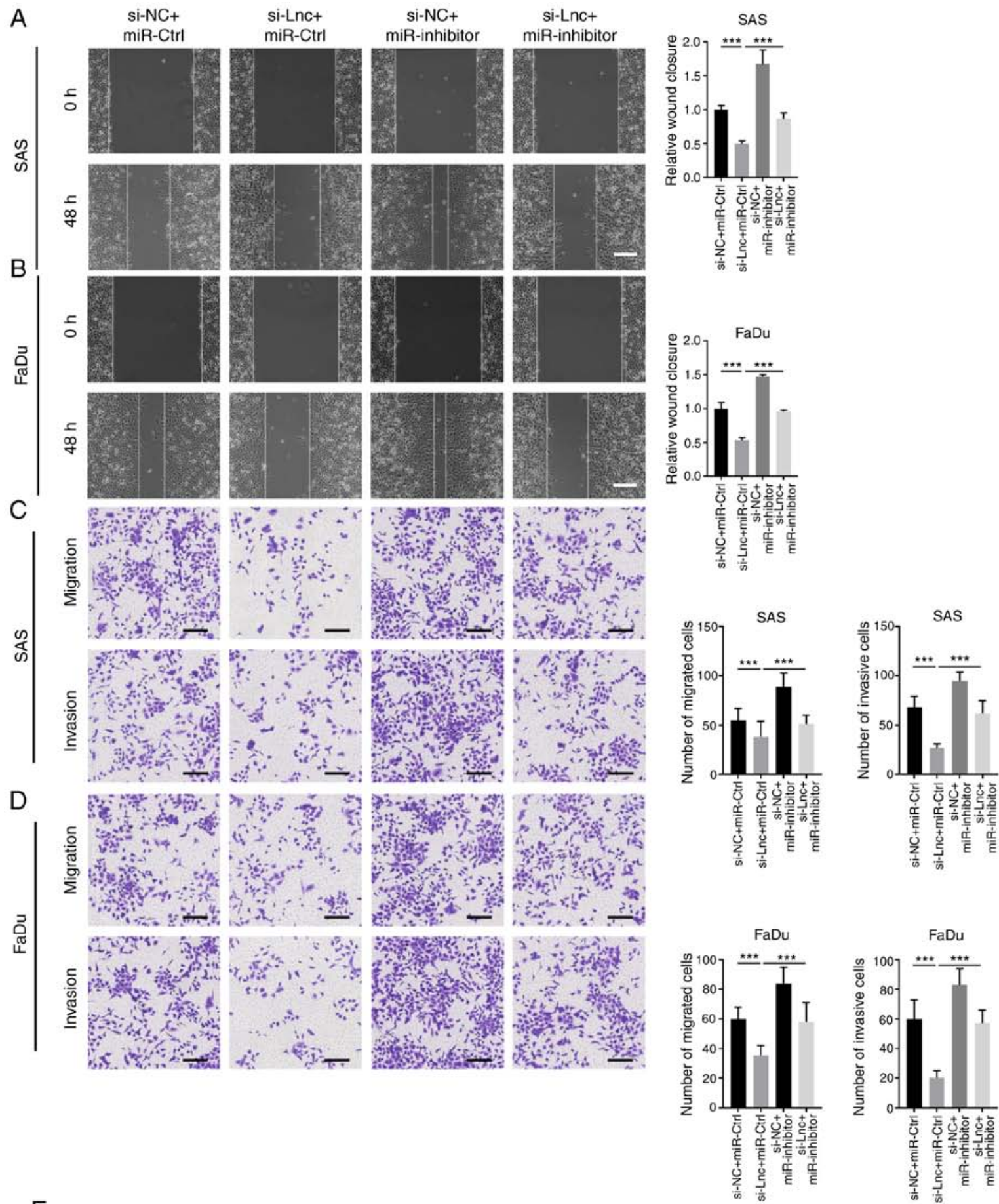

$\mathrm{E}$
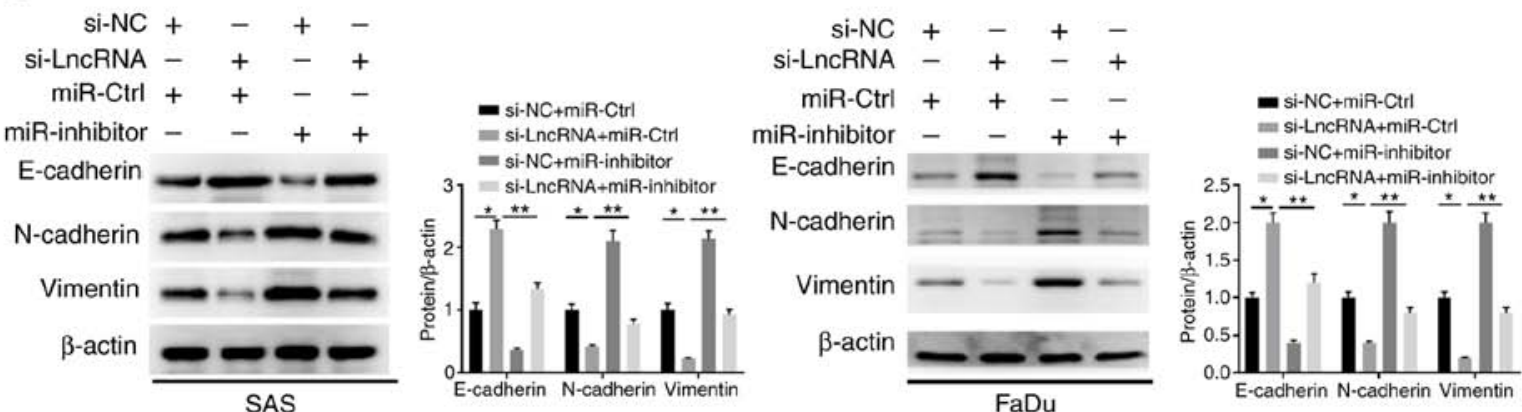

Figure 6. RP11-156L14.1 promotes migration, invasion, and EMT via miR-548-3p in HSCC cells. SAS or FaDu cells were transfected with si-NC+miR-Ctrl, si-RP11-156L14.1+miR-Ctrl, si-NC+miR-548ao-3p inhibitor, or si-RP11-156L14.1+miR-548ao-3p inhibitor. (A and B) Wound-healing assays were conducted to evaluate the cell migration of SAS and FaDu cells. (C and D) Transwell assays were performed to assess cell migration and invasion in SAS and FaDu cells. (E) EMT-related proteins E-cadherin, $\mathrm{N}$-cadherin, and vimentin were determined by western blotting in SAS and FaDu cells. $\beta$-actin was used as an internal control. The experiment was repeated three times, and the representative blot images are presented. ${ }^{*} \mathrm{P}<0.05,{ }^{* *} \mathrm{P}<0.01,{ }^{* * *} \mathrm{P}<0.001$. EMT, epithelial-mesenchymal transition; HSCC, hypopharyngeal squamous cell carcinoma. 
A

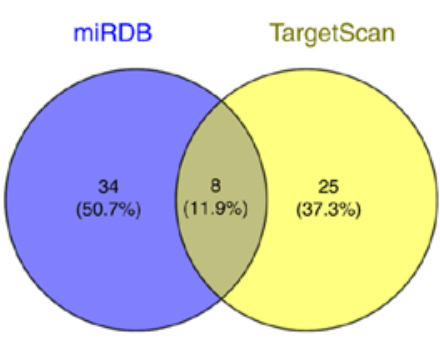

C
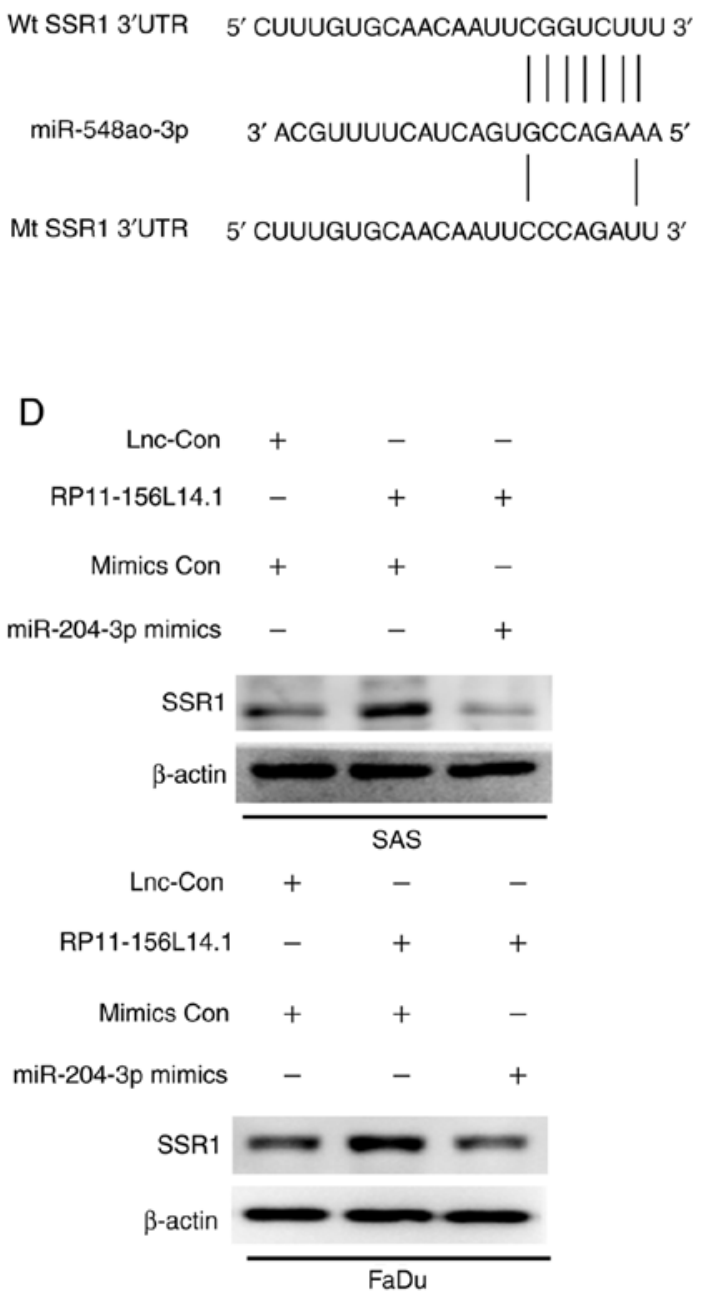

E

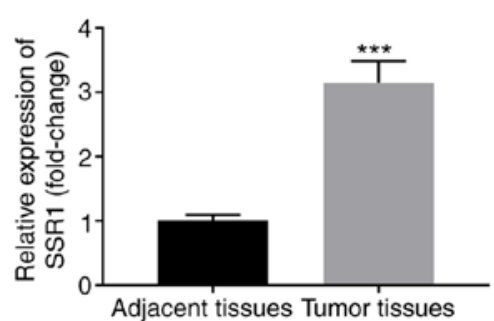

B
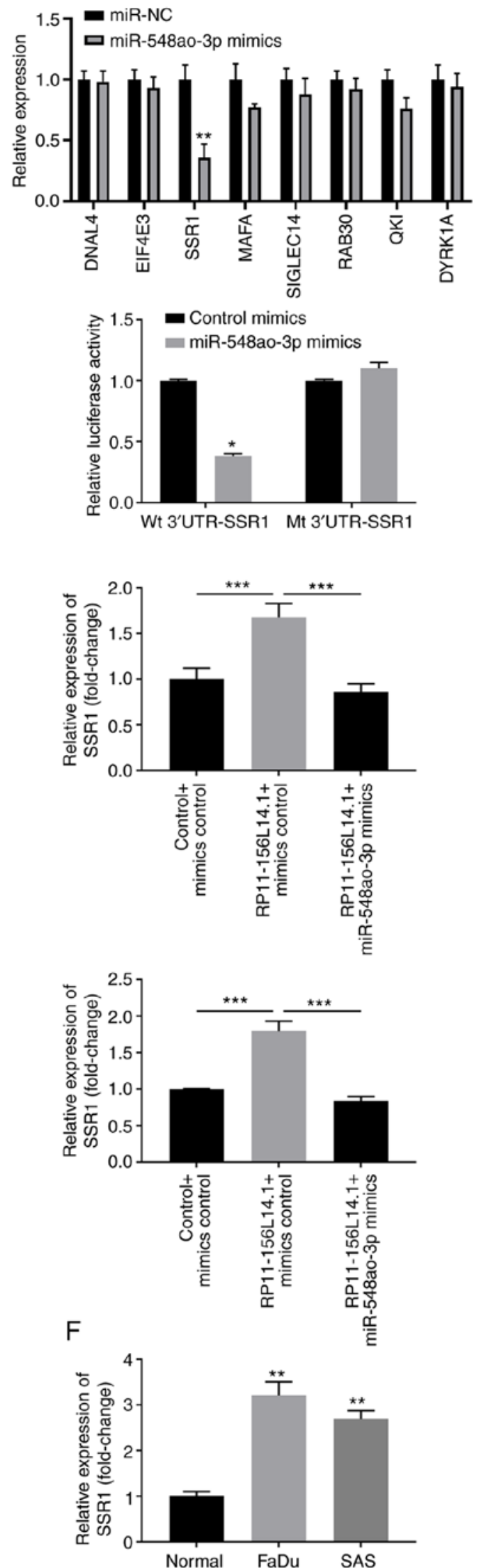

Figure 7. RP11-156L14.1 functions as a ceRNA in regulating SSR1 expression by binding to miR-548ao-3p. (A and B) Bioinformatics analyses predicted putative binding sequences between WT SSR1 3'-UTR and miR-548ao-3p. The mutated SSR1 3'-UTR sequences are listed. (C) 293 cells were transfected with control mimics or miR-548ao-3p mimics, in combination with reporter vectors containing Wt 3'-UTR SSR1 or mutated 3'-UTR of SSR1 sequences. Relative luciferase activity was measured $48 \mathrm{~h}$ later. (D) SAS or FaDu cells were transfected with pcDNA3.1 control, pcDNA3.1-RP11-156L14.1, or pcDNA3.1-RP11 $-156 \mathrm{~L} 14.1+\mathrm{miR}-548 \mathrm{ao}-3 \mathrm{p}$ mimics, and the protein levels of SSR1 were analyzed. $\beta$-actin was used as an internal control. The experiment was repeated three times, and the representative blot images are presented. (E) Relative expression of SSR1 in HSCC tumor tissues and adjacent non-tumor tissues was determined by qPCR. (F) Relative expression of SSR1 in HSCC cell lines and normal control cell was determined by qPCR. " $\mathrm{P}<0.05,{ }^{* *} \mathrm{P}<0.01,{ }^{* * * *} \mathrm{P}<0.001$. SSR1, signal sequence receptor subunit 1; WT, wild-type; HSCC, hypopharyngeal squamous cell carcinoma; qPCR, quantitative PCR. 
A

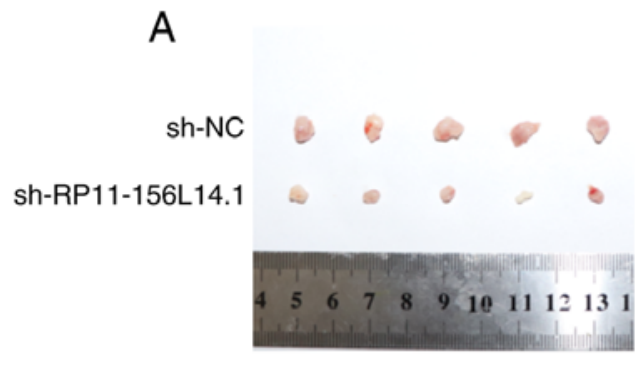

D

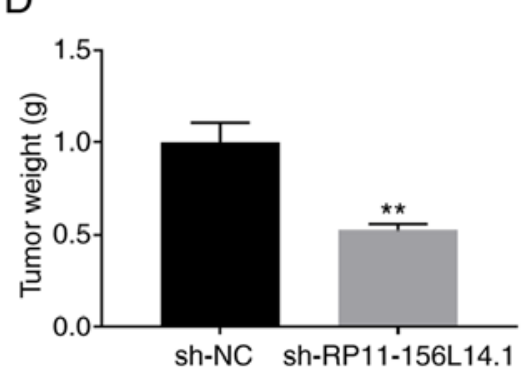

G

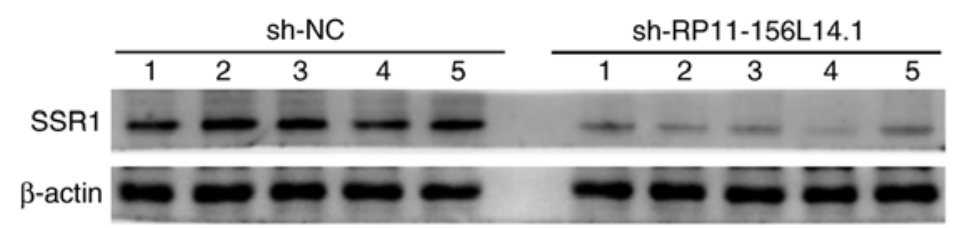

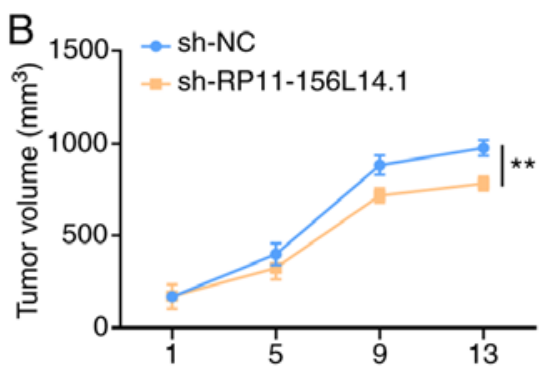

E

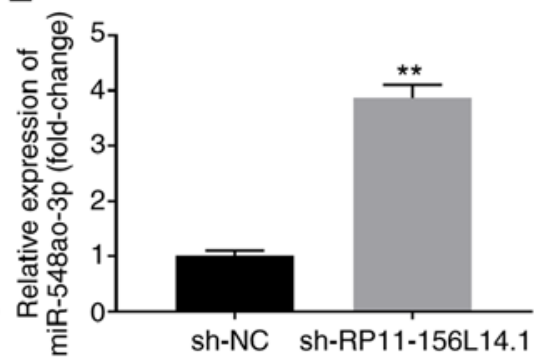

$\mathrm{F}$
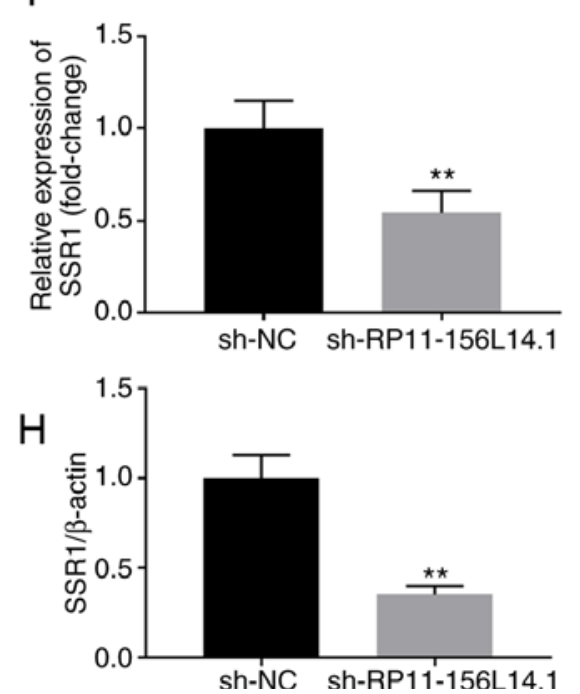

Figure 8. RP11-156L14.1 knockdown inhibits HSCC tumor growth in vivo. FaDu cells were transfected with sh-NC or sh-RP11-156L14.1 and then implanted subcutaneously into nude mice to develop tumors. (A) Images of tumor tissues from the sh-NC and sh-RP11-156L14.1 groups were obtained on day 13. (B) The growth curves of the tumor volume in nude mice were measured at the indicated time-points. (C and D) The volumes and weights of tumors from the sh-NC and sh-RP11-156L14.1 groups were measured on day 13. (E) The expression levels of miR-548ao-3p in the tumor tissues from the sh-NC and sh-RP11-156L14.1 groups were analyzed by RT-qPCR. (F-H) The relative mRNA and protein expression levels of SSR1 in the tumor tissues from the sh-NC and sh-RP11-156L14.1 groups were determined by RT-qPCR and western blotting. Data are presented as the mean $\pm \mathrm{SD}$. ${ }^{*} \mathrm{P}<0.05$, ${ }^{* *} \mathrm{P}<0.01$. HSCC, hypopharyngeal squamous cell carcinoma; RT-qPCR, reverse transcription-quantitative PCR.

expression in FaDu cells (Fig. 4E). Consistently, the expression level of miR-548ao-3p was markedly lower in HSCC tumor tissues and HSCC cell lines compared with that in adjacent normal tissues (Fig. 4F and G).

RP11-156L14.1 promotes cell proliferation and the cell cycle via miR-548ao-3p in HSCC cells. Next, the functional relationship between RP11-156L14.1 and miR-548ao-3p was further evaluated. While knockdown of RP11-156L14.1 increased miR-548ao-3p expression, miR-548ao-3p-inhibitor transfection downregulated the expression levels of miR-548ao-3p in SAS and FaDu cells (Fig. 5A and B). In SAS and FaDu cells, knockdown of RP11-156L14.1 inhibited cell proliferation and DNA synthesis and reduced the number of cells in the $S$ phase, while transfection of the miR-548ao-3p-inhibitor enhanced cell growth. However, SAS and FaDu cells transfected with miR-548ao-3p inhibitor combined with si-RP11-156L14.1 exhibited similar levels of cell proliferation, DNA synthesis and $\mathrm{S}$ phase percentage compared with the si-NC+miR-Ctrl group (Fig. 5C-F). The combined evidence indicated that lncRNA RP11-156L14.1 could promote cell proliferation and the cell cycle by competing with miR-548ao-3p in HSCC cells.

RP11-156L14.1 promotes migration, invasion, and EMT via miR-548ao-3p in HSCC cells. Further experiments were conducted to assess whether the function of RP11-156L14.1 in HSCC metastasis also depends on miR-548ao-3p. In SAS and FaDu cells, knockdown of RP11-156L14.1 inhibited cell migration and invasion, with reduced $\mathrm{N}$-cadherin/vimentin expression and enhanced E-cadherin expression (Fig. 6A-E). However, inhibition of miR-548ao-3p exhibited the opposite biological effects on cell migration/invasion in SAS and FaDu cells and partially abolished the effects of RP11-156L14.1 knockdown (Fig. 6A-E).

RP11-156L14.1 functions as a ceRNA in regulating SSR1 expression by binding to miR-548ao-3p. To investigate the potential target of miR-548ao-ep in HSCC, the bioinformatics analysis online tool TargetScan was used, which revealed that miR-548ao-3p targeted the 3'-UTR of SSR1 (Fig. 7A and B). A luciferase reporter assay was performed, and miR-548ao-3p mimics were found to inhibit the relative luciferase activity in 293 cells with reporter vectors transfected with the WT 3'-UTR of SSR1 but not the mutated 3'-UTR of SSR1 (Fig. 7C). To further confirm the relationship between RP11-156L14.1 and miR-548ao-3p in regulating SSR1, RP11-156L14.1 combined with miR-548ao-3p mimics was overexpressed in $\mathrm{SAS}$ or FaDu cells. The results revealed that overexpression of RP11-156L14.1 significantly upregulated SSR1 expression, while miR-548ao-3p decreased the expression of SSR1 
(Fig. 7D). Moreover, it was determined that the expression of SSR1 was significantly higher in HSCC tumor tissues and cell lines, compared with that in adjacent normal tissues (Fig. 7E-F).

RP11-156L14.1 knockdown inhibits tumor development and metastasis in HSCC in vivo. FaDu cells were stably transfected with the control vector or RP11-156L14.1 knockdown vector and subcutaneously implanted into the back flanks of nude mice to set up the xenograft tumor model. Knockdown of RP11-156L14.1 markedly inhibited tumor development, and the volumes and weights of xenograft tumors were significantly lower in the RP11-156L14.1-knockdown group compared with the sh-NC group (Fig. 8A-D). Additionally, miR-548ao-3p and SSR1 mRNA expression were analyzed in tumor tissues. As revealed in Fig. $8 \mathrm{E}$ and F, tumor tissues from the sh-RP11-156L14.1 group exhibited significantly higher expression levels of miR-548ao-3p, and significantly lower expression levels of SSR1. SSR1 protein levels were downregulated in the tumor tissues of the sh-RP11-156L14.1 group (Fig. 8G and $\mathrm{H}$ ). Overall, these data indicated that IncRNA RP11-156L14.1 knockdown suppressed HSCC growth in the xenograft model.

\section{Discussion}

Mounting studies have revealed that lncRNAs exert critical functions in HSCC progression and metastasis $(6,7)$. Notably, the present study delineated the biological function of RP11-156L14.1 in cell proliferation, migration, and invasion. Additionally, its interaction network with miR-548ao-3p and SSR1 was identified, indicating that RP11-156L14.1 could be utilized as a potential biomarker in HSCC.

RP11-156L14.1 is a novel lncRNA that was identified by genome scale analysis in squamous cell lung cancer (25). Another study revealed that RP11-156L14.1 was highly expressed in childhood T-cell acute lymphoblastic leukemia, potentially targeting the genes SMURF2, MAP3K3, and miRNA-633 (26). However, the function of RP11-156L14.1 in tumors, especially in HSCC, was not studied. In the present study, for the first time, to the best of our knowledge, it was demonstrated that RP11-156L14.1 was up-regulated in HSCC tumor tissues compared with adjacent non-tumor tissues. The enhanced expression of RP11-156L14.1 was also confirmed in HSCC cell lines. Due to the limited resources, we only examined the expression of RP11-156L14.1 in FaDu and SAS cells in the present study. RNA silencing assays were performed to assess the functions of RP11-156L14.1 in SAS and FaDu cells. Functional assays demonstrated that RP-11-156L14.1 acted as an oncogene and knockdown of RP-11-156L14.1 inhibited HSCC cell proliferation, migration, and invasion in vitro. The xenograft model revealed that knockdown of RP11-156L14.1 suppressed HSCC tumor development in vivo.

In a previous study, miRNA-633 was predicted to be the potential target of RP11-156L14.1 (26). In the present study, it was determined that RP11-156L14.1 directly interacted with miR-548ao-3p. miR-548ao-3p belongs to the large, poorly conserved primate-specific mir-548 family (27). miR-548-3p has been reported as a tumor suppressor in breast cancer, while miR-548q was revealed to be an oncogene and potential prognostic biomarker in gastric cancer (28). The present study revealed that miR-548ao-3p functioned as a tumor suppressor and the inhibition of miR-548ao-3p enhanced HSCC cell proliferation, migration, and invasion. Moreover, the data revealed that miR-548ao-3p mimics could antagonize the effects of RP11-156L14.1 overexpression. In contrast to the expression of RP11-156L14.1 in HSCC tumor tissues, miR-548ao-3p expression was significantly lower in HSCC tumor tissues compared with that in adjacent normal tissues.

To elucidate the target genes regulated by miR-548ao-3p, SSR1 was identified as a direct target gene controlled by miR-548ao-3p. SSR1 is a glycosylated membrane receptor related to protein translocation (29). A previous study has demonstrated that SSR1 may be used as a novel prognostic marker in renal and liver cancer $(30,31)$. The present study consistently determined that SSR 1 was highly expressed in HSCC and miR-548ao-3p regulated SSR 1 expression by binding to its 3'-UTR. However, the questions of whether SSR1 is also controlled by other miRNAs and how SSR1 regulates cell proliferation, migration, and invasion of HSCC cells require further investigation. Another limitation of the present study is that the signaling pathways involved in the regulation of the lncRNA RP11-156L14.1/miR-548ao-ep/SSR1 axis have not been defined yet.

In summary, the results of the present study demonstrated that lncRNA RP11-156L14.1 was enhanced in HSCC tissues and cell lines. Moreover, this study revealed that RP11-156L14.1 promoted HSCC development and metastasis by sponging miR-548ao-3p to regulate the expression of SSR 1 . The xenograft model revealed that knockdown of RP11-156L14.1 inhibited HSCC tumor growth in vivo. Overall, the IncRNA RP11-156L14.1/miR-548ao-3p/SSR1 axis provides novel insights into HSCC tumorigenesis and suggests a potential new biomarker for HSCC patients.

\section{Acknowledgements}

Not applicable.

\section{Funding}

The present study was supported by the Shaanxi Province Key R\&D Program General Project-Social Development Field (grant no. 2020SF-024), the Innovation Capability Support Program of Shaanxi (grant no. 2017KJXX-45), the Natural Science Foundation Group-style Aided Tibet Medical Project of Tibet Autonomous Region [grant no. XZ2019ZR-ZY72(Z)] and the Natural Science Basic Research Program of Shaanxi (grant no. 2018JM7023).

\section{Availability of data and material}

The datasets used and/or analyzed in the current study are available from the corresponding author upon reasonable request.

\section{Authors' contributions}

JH and GXZ conceived and designed the experiments. YY, HNL and XYR performed the experiments. NL, JY and ZHW 
analyzed the data. JY and ZHW wrote the manuscript. All authors read and approved the final manuscript.

\section{Ethics approval and consent to participate}

The investigation conformed to the principles outlined in the Declaration of Helsinki, and written informed consent was obtained from all participants. The Ethics Committee of the Second Affiliated Hospital of Xi'an Jiaotong University approved this study. The animal experiments were conducted under the protocol approval of the Ethics Committee of Animal Welfare of the Second Affiliated Hospital of Xi'an Jiaotong University.

\section{Patient consent for publication}

Not applicable.

\section{Competing interests}

The authors declare that they have no competing interests.

\section{References}

1. Katsoulakis E, Riaz N, Hu M, Morris L, Sherman E, McBride S and Lee N: Hypopharyngeal squamous cell carcinoma: Three-dimensional or intensity-modulated radiotherapy? A single institution's experience. Laryngoscope 126: 620-626, 2016.

2. Fukumoto I, Kinoshita T, Hanazawa T, Kikkawa N, Chiyomaru T, Enokida H, Yamamoto N, Goto Y, Nishikawa R, Nakagawa $\mathrm{M}$, et al: Identification of tumour suppressive microRNA-451a in hypopharyngeal squamous cell carcinoma based on microRNA expression signature. Br J Cancer 111: 386-394, 2014.

3. Takes RP, Strojan P, Silver CE, Bradley PJ, Haigentz M Jr, Wolf GT, Shaha AR, Hartl DM, Olofsson J, Langendijk JA, et al: Current trends in initial management of hypopharyngeal cancer: The declining use of open surgery. Head Neck 34: 270-281, 2012.

4. Chan JY and Wei WI: Current management strategy of hypopharyngeal carcinoma. Auris Nasus Larynx 40: 2-6, 2013.

5. Yang G, Lu X and Yuan L: LncRNA: A link between RNA and cancer. Biochim Biophys Acta 1839: 1097-1109, 2014.

6. Zhou J, Li W, Jin T, Xiang X, Li M, Wang J, Li G, Pan X and Lei D: Gene microarray analysis of lncRNA and mRNA expression profiles in patients with hypopharyngeal squamous cell carcinoma. Int J Clin Exp Med 8: 4862-4882, 2015.

7. Zhou J, Cao S, Li W, Wei D, Wang Z, Li G, Pan X and Lei D: Time-course differential lncRNA and mRNA expressions in radioresistant hypopharyngeal cancer cells. Oncotarget 8: 40994-41010, 2017.

8. Qian Y, Liu D, Cao S, Tao Y, Wei D, Li W, Li G, Pan X and Lei D: Upregulation of the long noncoding RNA UCA1 affects the proliferation, invasion, and survival of hypopharyngeal carcinoma. Mol Cancer 16: 68, 2017.

9. Zhou J, Li M, Yu W, Li W, Wang J, Xiang X, Li G, Pan X and Lei D: AB209630, a long non-coding RNA decreased expression in hypopharyngeal squamous cell carcinoma, influences proliferation, invasion, metastasis, and survival. Oncotarget 7: 14628-14638, 2016.

10. Zhao M, Sun D, Li X, Xu Y, Zhang H, Qin Y and Xia M: Overexpression of long noncoding RNA PEG10 promotes proliferation, invasion and metastasis of hypopharyngeal squamous cell carcinoma. Oncol Lett 14: 2919-2925, 2017.

11. Zhang CZ: Long intergenic non-coding RNA 668 regulates VEGFA signaling through inhibition of miR-297 in oral squamous cell carcinoma. Biochem Biophys Res Commun 489 : 404-412, 2017.

12. Lee SH, Koo BS, Kim JM, Huang S, Rho YS, Bae WJ, Kang HJ, $\mathrm{Kim}$ YS, Moon JH and Lim YC: Wnt/ $\beta$-catenin signalling maintains self-renewal and tumourigenicity of head and neck squamous cell carcinoma stem-like cells by activating Oct 4 . J Pathol 234: 99-107, 2014.
13. Huang W, Cui X, Chen J, Feng Y, Song E, Li J and Liu Y: Long non-coding RNA NKILA inhibits migration and invasion of tongue squamous cell carcinoma cells via suppressing epithelial-mesenchymal transition. Oncotarget 7: 62520-62532, 2016.

14. van Kester MS, Tensen CP, Vermeer MH, Dijkman R, Mulder AA, Szuhai K, Willemze R and van Doorn R: Cutaneous anaplastic large cell lymphoma and peripheral T-cell lymphoma NOS show distinct chromosomal alterations and differential expression of chemokine receptors and apoptosis regulators. J Invest Dermatol 130: 563-575, 2010.

15. Ali MM, Akhade VS, Kosalai ST, Subhash S, Statello L, Meryet-Figuiere M, Abrahamsson J, Mondal T and Kanduri C: PAN-cancer analysis of S-phase enriched lncRNAs identifies oncogenic drivers and biomarkers. Nat Commun 9: 883, 2018.

16. Nair VS, Maeda LS and Ioannidis JP: Clinical outcome prediction by microRNAs in human cancer: A systematic review. J Natl Cancer Inst 104: 528-540, 2012.

17. Kikkawa N, Hanazawa T, Fujimura L, Nohata N, Suzuki H, Chazono H, Sakurai D, Horiguchi S, Okamoto Y and Seki N: miR-489 is a tumour-suppressive miRNA target PTPN11 in hypopharyngeal squamous cell carcinoma (HSCC). Br J Cancer 103: 877-884, 2010.

18. Kikkawa N, Kinoshita T, Nohata N, Hanazawa T, Yamamoto N, Fukumoto I, Chiyomaru T, Enokida H, Nakagawa M, Okamoto Y and Seki N: microRNA-504 inhibits cancer cell proliferation via targeting CDK6 in hypopharyngeal squamous cell carcinoma. Int J Oncol 44: 2085-2092, 2014.

19. Zhang C, Wang C, Jia Z, Tong W, Liu D, He C, Huang X and $\mathrm{Xu}$ W: Differentially expressed mRNAs, IncRNAs, and miRNAs with associated co-expression and ceRNA networks in ankylosing spondylitis. Oncotarget 8: 113543-113557, 2017.

20. Guan GF, Zhang DJ, Wen LJ, Xin D, Liu Y, Yu DJ, Su K, Zhu L, Guo YY and Wang K: Overexpression of lncRNA H19/miR-675 promotes tumorigenesis in head and neck squamous cell carcinoma. Int J Med Sci 13: 914-922, 2016.

21. Zhuang K, Wu Q, Jiang S, Yuan H, Huang S and Li H: CCAT1 promotes laryngeal squamous cell carcinoma cell proliferation and invasion. Am J Transl Res 8: 4338-4345, 2016

22. Kolenda T, Guglas K, Kopczyńska M, Teresiak A, Bliźniak R, Mackiewicz A, Lamperska K and Mackiewicz J: Oncogenic role of ZFAS1 lncRNA in head and neck squamous cell carcinomas. Cells 8: 366, 2019.

23. Livak KJ and Schmittgen TD: Analysis of relative gene expression data using real-time quantitative PCR and the 2(-Delta Delta C(T)) method. Methods 25: 402-408, 2001.

24. Nijkamp MM, Span PN, Hoogsteen IJ, van der Kogel AJ, Kaanders JH and Bussink J: Expression of E-cadherin and vimentin correlates with metastasis formation in head and neck squamous cell carcinoma patients. Radiother Oncol 99: 344-348, 2011.

25. Wang Y, Qian CY, Li XP, Zhang Y, He H, Wang J, Chen J, Cui JJ, Liu R, Zhou H, et al: Genome-scale long noncoding RNA expression pattern in squamous cell lung cancer. Sci Rep 5: 11671, 2015.

26. Remke M, Pfister S, Kox C, Toedt G, Becker N, Benner A, Werft W, Breit S, Liu S, Engel F, et al: High-resolution genomic profiling of childhood T-ALL reveals frequent copy-number alterations affecting the TGF-beta and PI3K-AKT pathways and deletions at 6q15-16.1 as a genomic marker for unfavorable early treatment response. Blood 114: 1053-1062, 2009.

27. Liang T, Guo L and Liu C: Genome-wide analysis of mir-548 gene family reveals evolutionary and functional implications. J Biomed Biotechnol 2012: 679563, 2012.

28. Shi Y, Qiu M, Wu Y and Hai L: MiR-548-3p functions as an anti-oncogenic regulator in breast cancer. Biomed Pharmacother 75: 111-116, 2015.

29. Vogel F, Hartmann E, Görlich D and Rapoport TA: Segregation of the signal sequence receptor protein in the rough endoplasmic reticulum membrane. Eur J Cell Biol 53: 197-202, 1990.

30. Poplawski P, Wiśniewski JR, Rijntjes E, Richards K, Rybicka B, Köhrle J and Piekiełko-Witkowska A: Restoration of type 1 iodothyronine deiodinase expression in renal cancer cells downregulates oncoproteins and affects key metabolic pathways as well as anti-oxidative system. PLoS One 12: e0190179, 2017.

31. Rao CV, Asch AS and Yamada HY: Frequently mutated genes/pathways and genomic instability as prevention targets in liver cancer. Carcinogenesis 38: 2-11, 2017.

This work is licensed under a Creative Commons Attribution-NonCommercial-NoDerivatives 4.0 International (CC BY-NC-ND 4.0) License. 